\title{
Participação popular e produção de políticas de habitação: os casos de Porto Alegre e São Paulo
}

Popular participation and production of housing policies: the cases of Porto Alegre and São Paulo

\author{
Cristine Jaques Ribeiro* \\ Renan Costa Valle Scarano**
}

\begin{abstract}
Resumo
O presente texto trata de políticas públicas de habitação nos casos das cidades de Porto Alegre-RS e São Paulo-SP. Trata-se de duas cidades brasileiras que no final dos anos 1980 e início dos anos 1990 construíram um processo político em que poder público e participação popular estiveram imbricados na construção de políticas de habitação. Diante do programa Minha Casa, Minha Vida, modelo centralizador e universalizado em solo brasileiro de política de habitação, e que contou com o protagonismo de empresas ligadas a área da construção civil, os casos de Porto Alegre e São Paulo, através do Orçamento Participativo e da participação popular, colocam-se como processos que aproximam poder público e sociedade civil. Desta forma, tais processos democráticos parecem oferecer um horizonte para a política de habitação que contrasta com o modelo da democracia representativa hegemônica na história do Brasil. A metodologia do trabalho é pesquisa bibliográfica e documental. Através da pesquisa verificou-se que os casos das cidades de Porto Alegre e São Paulo oferecem processos políticos em que é possível construir uma política de habitação democrática em que Estado e sociedade civil convergem.
\end{abstract}

Palavras-chave: Direito à cidade. Democracia. Habitação. Estado.

\begin{abstract}
The present text deals with public housing policies in the cities of Porto Alegre / RS and São Paulo / SP. Two Brazilian cities built a political process in which public power and popular participation were intertwined in the construction of housing policies. Given the Minha Casa, Minha Vida, a centralizing and universalized model in Brazilian housing policy soil, which had the leading role of companies linked to the construction area, the cases of Porto Alegre and São Paulo, through the Participatory Budget and popular participation stand as processes that bring public power and civil society closer. Thus, such democratic processes seem to offer a horizon for housing policy that contrasts with the model of hegemonic representative democracy in Brazilian history. The methodology of the work is bibliographic and documentary research. Through research it was found that the cases of the cities of Porto Alegre and São Paulo offer political processes in which it is possible to build a democratic housing policy in which state and civil society converge.
\end{abstract}

Keywords: Right to the city. Democracy. Housing. Capitalism. State

\footnotetext{
* Doutora Serviço Social PUCRS; Docente no Curso de Pós-graduação em Política Social e Direitos Humanos e graduação em Serviço Social/UCPel; Coordenadora GEP Questão Agrária, Urbana e Ambiental/Observatório dos Conflitos da Cidade; Coordenação Fórum em defesa da Soberania e Segurança alimentar e nutricional Pelotas.

** Doutorando em Política Social e Direitos Humanos na Universidade Católica de Pelotas; Mestre em Política Social pela UCPel e membro do Observatório de Conflitos da Cidade.
} 


\section{Introdução}

O processo de transformação da sociedade brasileira, de rural à urbana, produziu-se de forma predatória e desigual. Autoras como Maricato (2003) apontam que a realidade urbana brasileira revela problemas de ordem territorial, social e ambiental que são agravadas pela grande desigualdade socioeconômica presente nas cidades. Assim, as periferias, tanto das regiões metropolitanas quanto das grandes cidades, refletem a precariedade e vulnerabilidade que a vida urbana oferece para alguns. Isso é expresso na inconsistência da prestação de serviços, como falta de acesso ao saneamento básico para ocupações em áreas de encostas e de mananciais, habitações inadequadas, falta de segurança etc.

Por outro lado, existe uma parcela da população que possui acesso à vida urbana e, portanto, a liberdade de acesso àquilo que a infraestrutura das cidades oferece. Desse modo, pode-se observar que os serviços públicos, como o acesso à saúde, à segurança, ao transporte público, assegurados pela Constituição Federal de 1988, não são oferecidos para toda a população.

Na Constituição Federal Brasileira de 1988, a moradia aparece enquanto direito social no artigo 6으, com a educação, o transporte, a segurança, entre outros. A mesma constituição, em seu capítulo II, artigos 182 e 183, trata da política urbana, cuja função é "ordenar o pleno desenvolvimento das funções sociais da cidade e garantir o bem-estar de seus habitantes." (BRASIL, 1988). Se a Constituição, por um lado, afirma que o direito à moradia, à habitação, enquanto direito social, é para todos, por outro, na prática, tal direito não é concretizado de modo universal. Isso significa que o direito à cidade não é acessível a todos cidadãos. Enquanto alguns grupos sociais possuem acesso aos direitos e aos bens econômicos, outros ficam à margem.

O Brasil tem registrado políticas públicas de habitação de largo alcance e de cunho centralizador, entre as quais destacam-se o Banco Nacional de Habitação (BNH), de 1965 a 1980, e o Minha Casa, Minha Vida, de 2008 a 2015. Tais programas parecem ser insuficientes no que tange o déficit habitacional e a desigualdade social que, todavia, permanecem como grandes desafios na realidade brasileira. Por outro lado, historicamente, a sociedade civil, através dos movimentos sociais e da participação popular, tem atuado na luta pela moradia e pela reforma urbana.

A metodologia utilizada para este trabalho foi a pesquisa bibliográfica e documental. Na pesquisa documental utilizou-se dados do site da Fundação João Pinheiro sobre o déficit habitacional no país. 
O objetivo deste texto é apresentar duas realidades locais em que a política habitacional foi construída numa relação entre sociedade civil, movimentos populares e poder público na produção de políticas públicas de habitação. Tais casos são colocados em contraponto ao modelo centralizador do Programa Minha Casa, Minha Vida, em que o Estado e o Mercado aparecem como protagonistas da política habitacional. Num primeiro momento dá-se destaque a alguns fatos sobre o processo histórico urbano no Brasil e num segundo momento apresenta-se os casos de Porto Alegre e São Paulo, que no início da década de 1990 buscavam a produção de políticas habitacionais congregando a participação popular no processo democrático. Por fim, conclui-se que os casos referidos oferecem processos políticos em que é possível construir uma política de habitação democrática em que há uma conversão entre Estado e sociedade civil.

\section{A Produção do Espaço Urbano no Brasil: Aspectos Históricos}

O rápido aumento da população urbana foi um dos fatores que agravou a questão urbana no Brasil. De acordo com Maricato (2003, p. 151), até o final do século XIX, a grande população permanecia no campo, enquanto a população urbana, "totalizava entre 6,8 a 10\% em 1890". No entanto, no início do século XX, as cidades brasileiras passam a ser vistas como "possibilidade de avanço e modernidade em relação ao campo que representava o Brasil arcaico." (MARICATO, 2003, p. 151). Deste modo, com a regulamentação do trabalho urbano, com o incentivo à industrialização, a construção da infraestrutura industrial, entre outras medidas, a população é incentivada a migrar para as cidades (MARICATO, 2003).

Dois fatores foram marcantes para que se iniciasse a industrialização no Brasil: o primeiro foi a impulso provocado pelo poder público e a segunda foi a posição que o mercado interno passa a ocupar na elaboração econômica e territorial do país (SANTOS, 1993). Nesse contexto, explicam Ramos e Noia (2016), o Estado passou a investir em infraestrutura urbana e regional para dar apoio ao processo industrial. Assim, a cidade surgia como um campo de oportunidades para a população.

Nos anos 1940 e 1950 passou a prevalecer a lógica da industrialização, e tais mudanças engendraram a regulamentação do trabalho urbano, o que reforçou o movimento migratório campo-cidade. No entanto, Santos (1993, p. 27) adverte que o termo industrialização, utilizado aqui, não deve ser tomado em seu sentido estrito "como criação de atividades industriais nos lugares", mas, em sua ampla significação, como o processo social 
complexo. Isso significa que industrialização deve ser entendida como um processo complexo que inclui a formação de um mercado nacional, [...] quanto os esforços de equipamento do território para torná-lo integrado, como a expansão do consumo em formas diversas, o que impulsiona a vida de relações (leia-se terceirização) e ativa o próprio processo de urbanização (SANTOS, 1993, p. 27).

O processo da industrialização no Brasil foi crucial na visão de Santos (1993) para que se agravasse as condições de vida das populações na cidade. Entre as décadas de 1960 e 1980, ocorreu no Brasil um acréscimo em mais de $20 \%$ na população que passou a habitar os centros urbanos, aproximadamente 50 milhões de pessoas, o que provocou o agravamento da questão urbana (MARICATO, 2003). Com o crescimento urbano há uma sobrecarga na necessidade de infraestrutura e equipamentos, afetando o funcionamento da cidade como um todo e comprometendo a vida da população (RUBIN; BOLFE, 2014).

Outro aspecto a ser enfrentado no Brasil em sua acelerada urbanização diz respeito às inadequadas condições de moradias enfrentadas pelas populações de baixa renda. Nessa perspectiva, num sentido de enfrentamento aos problemas que surgem no espaço urbano, projetam-se políticas públicas e intervenções urbanas a fim de acabar com os agravos ou diminuir a problemática resultante do crescimento urbano. De acordo com Ramos e Noia (2016), a questão habitacional reflete a disparidade da desigualdade social brasileira. Em relação a isso, os autores defendem que a alta concentração da propriedade, no Brasil, foi acompanhada de uma extrema desigualdade na distribuição de renda da população. Para Santos (1993, p. 10),

[...] o processo brasileiro de urbanização revela uma crescente associação com o da pobreza, cujo locus passa a ser, cada vez mais, a cidade, sobretudo a grande cidade. O campo brasileiro moderno repele os pobres, e os trabalhadores da agricultura capitalizada vivem cada vez mais nos espaços urbanos. A indústria se desenvolve com a criação de pequeno número de empregos e o terciário associa formas modernas às formas primitivas que remuneram mal e não garantem a ocupação.

Ramos e Noia (2016, p. 68) ainda salientam que o intenso processo de urbanização ocorrido no Brasil "não foi acompanhado pelas oportunidades de empregos, nem pela oferta de moradias, infraestrutura e serviços urbanos, implicando a ocupação desordenada do solo e a expansão contínua das periferias".

No início da década de 1950, a estimativa do déficit habitacional era de "3,6 milhões de moradias, desconsiderando-se os cortiços e as favelas que já eram bastante comuns na 
paisagem dos grandes centros urbanos." (RAMOS; NOIA, 2016, p. 68). Os mesmos autores apontam que, no início da década de 80, "um estudo do Banco Nacional de Habitação divulgou que a estimativa das necessidades habitacionais ultrapassava 6 milhões de moradias, concentradas, principalmente, na faixa de até 3 salários mínimos." (RAMOS; NOIA, 2016, p. 68).

A fim de suprir o déficit habitacional, no ano de 1964 foi aprovada a Lei n. 4.380, que instituía a correção monetária de Interesse Social, o Sistema Financeiro para aquisição da Casa Própria, o Banco Nacional da Habitação (BNH), e Sociedades de Crédito Imobiliário, as Letras Imobiliárias, o Serviço Federal de Habitação e Urbanismo (RIBEIRO, 2013).

O objetivo da política de habitação social via BNH visava o financiamento da casa própria para populações de baixa renda, no entanto, tal política "foi sendo apropriada pelas classes de maior poder aquisitivo [...]." (RIBEIRO, 2013, p. 3), desta forma, o direito à habitação não foi concretizado para todas as classes. Nos anos de ditadura civil-militar, mais exatamente entre os anos 1970-1980, “o crescimento numérico da população urbana já era maior que o da população total." (SANTOS, 1993, p. 30). Nessa época, o problema da moradia foi encarado através do conceito de déficit habitacional. Bolaffi $(1982$, p. 53) defende que o problema da habitação popular foi selecionado "como uma das prioridades básicas sobre as quais devia concentrar-se o esforço econômico da nação, a partir do conceito de déficit habitacional." Ou seja, através de políticas públicas como o BNH, financiavam-se e produziam-se moradias a fim de acabar com o déficit habitacional.

No entanto, de acordo com o relatório anual do BNH, no ano de 1971, "os recursos utilizados pelo Sistema Financeiro da Habitação só foram suficientes para atender a $24 \%$ da demanda populacional (urbana)." (BOLAFFI, 1982, p. 53). Ou seja, 6 anos após a criação do $\mathrm{BNH}$, sua contribuição para acabar ou diminuir com o déficit habitacional, foi insuficiente, pois sua atuação acabou aumentando o déficit em 76\% (BOLAFFI, 1982).

O final dos anos 1980 e 1990 são marcados pelas políticas habitacionais que eram planejadas no âmbito local, ou seja, o poder público não era o principal articulador das políticas. Isso se deu devido à crise do Sistema Financeiro de Habitação (SFH) e à extinção do Banco Nacional de Habitação (BNH), em 1986 (SANTOS, 2005).

A partir dos anos 1990, a fim de amenizar o déficit habitacional, o Estado utilizou-se da seguinte estratégia: urbanizar as favelas, potencializando investimento em equipamentos públicos que atendam a população (RIBEIRO, 2013). No entanto, ao mesmo tempo, verificase uma ausência de políticas públicas de habitação com o protagonismo do Estado. Tem-se "a 
nova política de habitação que emergiu nos anos 90 objetivava, através de uma abordagem participativa, implementar programas e projetos para integrar a população marginalizada à cidade formal." (GOMES, 2005). Durante os governos Fernando Henrique Cardoso (19951998; 1999-2003), a Secretaria Nacional de Habitação estava subordinada ao Ministério de Planejamento e Orçamento. Entretanto, foi a Secretaria Especial de Desenvolvimento Urbano, vinculada à Presidência da República, que se responsabilizou pelas instituições ligadas à política habitacional até 2003 , quando houve a criação do Ministério das Cidades, em que se alocou a Secretaria Nacional de Habitação (SANTOS, 2005).

Em 2004, como resultado de ciclos de debates e seminários em que o Conselho das Cidades exerceu importante papel, elaborou-se a Política Nacional de Habitação (RIBEIRO, 2013). A Política Nacional de Habitação tinha por objetivo "retomar o processo de planejamento do setor habitacional e garantir novas condições institucionais para promover o acesso à moradia digna a todos os segmentos da população." (BRASIL, 2004, p. 7). A fim de implementar a Política Nacional de Habitação, com o intuito de implementar políticas e programas que promovam o acesso à moradia digna para a população de baixa renda, no ano de 2005 instituiu-se pela Lei 11.124/2005 o Sistema Nacional de Habitação de Interesse Social (SNHIS). De acordo com o capítulo 1ํㅡ, art.2ํ, da Lei 11.124/2005, ficava instituído que o SNHIS tinha por objetivo:

I - viabilizar para a população de menor renda o acesso à terra urbanizada e à habitação digna e sustentável; II - implementar políticas e programas de investimentos e subsídios, promovendo e viabilizando o acesso à habitação voltada à população de menor renda; e III - articular, compatibilizar, acompanhar e apoiar a atuação das instituições e órgãos que desempenham funções no setor da habitação (BRASIL, 2005).

Em 2009 criou-se o "Minha Casa, Minha Vida", esperava-se com tal programa que a política de habitacional fosse atendida. No entender de Rolnik (2015) com a expansão do Minha Casa, Minha Vida, os programas municipais e as políticas locais voltadas para as cidades acabaram sendo enfraquecidos enquanto que o Minha Casa, Minha Vida, passou a vigorar em todo território nacional como política habitacional. Na visão de Rolnik (2015), o Minha Casa, Minha Vida, foi "desenhado para incentivar empresas privadas a se comprometerem com a produção de habitação para moradores de baixa renda." (ROLNIK, 2015, p. 309), mas não foi o que aconteceu. Conforme analisa a autora, o déficit habitacional quantitativo (demanda por residências próprias ou alugadas) não sofreu alterações significativas. Em 2009, o déficit 
alcançava 6 milhões de moradias e passou para 6,1 milhões em 2014, ou seja, aumento de 1,6\% (BÖHM, 2018). Já em 2014 e 2015, de acordo com a Fundação João Pinheiro (2018), o déficit habitacional do país havia aumentado em 20 dos 27 estados da federação.

Em 2009, quando se põe em prática o programa Minha Casa, Minha Vida, cabe destacar que apenas 1,5\% foi destinado ao Programa Minha Casa Minha Vida entidades. Enquanto isso, $98,5 \%$ dos recursos federais foram destinados para o modelo tradicional do Minha Casa, Minha Vida.

O Programa Minha Casa Minha Vida Tradicional era intermediado pelas grandes incorporadoras imobiliárias, ao passo que o Minha Casa Minha Vida Entidades tratava os recursos do Governo Federal, diretamente sob a forma de cooperativas, associações de moradores, entre outras (DILIGENTI; FERNANDES; CAMPOS, 2017, p. 21).

Embora muitas pessoas tenham alcançado "o sonho" da casa própria através do programa Minha Casa, Minha Vida, a construção e a entrega de mais de 4 milhões de moradias durante o programa (2009-2015) gerou um aumento no déficit habitacional. Além disso, criou outro problema nas cidades brasileiras, a dispersão nas cidades, ou seja, as distâncias nas cidades se estenderam, junto a isso soma-se os agravantes deste problema (MARICATO, 2019).

Com alguns aspectos históricos postos à mesa, pensa-se que a história da produção do espaço urbano no Brasil deve ser situada em consonância ao sistema capitalista. Isso quer dizer que o espaço urbano é um campo de disputa onde atuam diferentes agentes com diferentes condições de acesso ao urbano. Acesso via capital econômico e acesso via capital político, isto é, através do direito à habitação. Nesse sentido, o Estado é um ente que sempre está em disputa pelos diferentes agentes a fim de assegurar o direito à habitação. Nesse sentido, as políticas púbicas de habitação social, asseguradas pelo direito à habitação, previsto na Carta magna dos Direitos Humanos e na Constituição Federal do Brasil de 1988, visam conferir acesso à moradia às famílias de baixa renda, além de enfrentar o déficit habitacional.

Desta forma, defende-se que aquelas populações que necessitam de tal política sejam os agentes que participam do processo de decisão de onde e como morar. Ao contrário, nota-se que a participação popular é renegada a uma posição passiva de quem está recebendo um benefício, em vez de ser agente de uma política pública. Como forma de abordar tal questão, apresenta-se dois casos em diferentes regiões do país: Porto Alegre e São Paulo, onde se sabe que o contexto dos processos de criação de políticas habitacionais era marcado 
por um fortalecimento da democracia. Deste modo, ressalta-se a importância dos agentes locais envolvidos na construção, decisão e acesso à política de habitação.

\section{Porto Alegre e São Paulo: Duas Experiências de Políticas Públicas de Habitação Municipal Através da Participação Popular}

Com a criação e implementação do Programa Minha Casa, Minha Vida, houve uma centralização da política habitacional no âmbito nacional, além da centralização dos recursos federais para execução de tal política. Em 2009, houve uma intensificação, a nível federal, das políticas públicas na área de habitação de interesse social, sobretudo, através do Programa Minha Casa, Minha Vida. No entanto, no entender de Diligenti, Fernandes e Campos (2017), tal programa buscou obter resultados quantitativos na produção de moradias, além de centralizar as políticas de habitação, sobretudo, no que tange ao acesso aos recursos para concretizar a política de habitação no programa.

Os casos de Porto Alegre e de São Paulo, no final dos anos 1980 e início dos anos 1990, demonstram que é possível construir uma política habitacional em que haja participação popular em diversas esferas do processo de produção de uma política pública. A discussão sobre a habitação envolve diversos tipos de conhecimentos e competências. Nesse jogo, há um envolvimento dos órgãos públicos, dos interesses do mercado, do conhecimento oferecido por técnicos, mas, e a população?

Discutir sobre onde e como morar é realizar um exercício de cidadania, é concretizar o exercício efetivo de direitos individuais, políticos e sociais que são assegurados pela Constituição Federal de 1988. Ou seja, a participação no processo de deliberação e de produção de uma política de habitação possui grande importância para as pessoas que estão envolvidas com o problema. Nessa perspectiva, os Conselhos e outros mecanismos de participação, como o Orçamento Participativo, foram órgãos criados num contexto em que a democracia participativa era um horizonte perseguido pelos governantes e por parte da sociedade civil. Amaral (2002, p. 3) afirma que a "existência dos Conselhos e de outros processos de participação na gestão municipal é uma conquista da sociedade que se mobilizou para criá-los e um avanço de governantes empenhados na construção de uma nova forma democrática de governar."

No caso de Porto Alegre, abordado por Diligenti, Fernandes e Campos (2017), desde o ano de 1955, com a criação do Departamento Municipal da Casa Popular (DMCP), o poder público atuou na construção e na desapropriação de grandes extensões de terra para a 
habitação popular. Durante a época do governo civil-militar, houve uma reestruturação por meio da Lei 2.092 de 1965, em que o DMCP foi transformado no Departamento Municipal de Habitação Social (DMHAB). O DEMHAB iniciou suas atividades em 1970, com investimentos federais oriundos do BNH até 1986, quando este órgão deixou de existir. Entre os programas do governo federal que os autores citam, destacam-se: o PRO-GENTE, em 1975, PLANHAP (Plano Nacional de Habitação Popular), em 1976, PROLIFURB (Programa de Financiamento de Lotes Urbanizados), em 1979, FICAM (Programa de Construção, Conclusão, Ampliação e Melhoria da Habitação de Interesse Social), em 1979, e o PROMORAR (Programa de Erradicação de Submoradias), em 1980 (DILIGENTI; FERNANDES; CAMPOS, 2017).

Uma vez acabado o programa federal, observou-se que a meta de atender as camadas pobres da população não havia sido atingida.

Verificou-se que aproximadamente $70 \%$ dos contratos firmados sob esse instrumento financeiro eram voltados para as classes média e média alta, o Governo Federal não propôs nenhum programa substituto no sentido de atender à demanda de Habitação de Interesse Social (DILIGENTI; FERNANDES; CAMPOS, 2017, p. 7).

No entanto, em Porto Alegre, com a institucionalização do Orçamento Participativo, em 1989, as questões relacionadas à habitação passaram a fazer parte da agenda municipal. Nesse sentido, a lógica da democracia representativa, em que as decisões impactantes na vida da população ocorrem na dinâmica da representatividade, passou a ser subvertida.

\footnotetext{
Ao trazer para a esfera decisória a possibilidade deliberativa direta das comunidades na escolha dos investimentos públicos da cidade, representou um marco no sentido de intensificar a participação popular em todas as esferas de decisões e particularmente no caso habitacional, nas possibilidades de onde e como morar (FEDOZZI, 1997 apud DILIGENTI; FERNANDES; CAMPOS, 2017, p. 7).
}

Cabe salientar também que este período é marcado pela falta de programas do governo federal para tratar o tema da questão habitacional. Em contrapartida, através do DEMHAB houve a criação de novos programas e projetos na cidade, e tais programas eram financiados pelo Fundo Municipal de Habitação e direcionados pela participação popular. Entre os projetos realizados de maneira democrática participativa destacam-se o Programa de incentivo às cooperativas habitacionais de 1990 e o Orçamento Participativo, em que havia um vínculo e uma participação popular.

A falta de regularização fundiária também foi encarada como um problema. Nesse sentido, a prefeitura criou o Programa de Regularização Fundiária que, a partir de 1993, 
passou a ser exclusivamente competência do DEMHAB. Outro programa criado para enfrentar os dilemas da questão habitacional foi o Programa de Cooperativismo Habitacional Autogestionário. Tal programa induziu a organização de grupos em cooperativas destinadas a: aquisição de terrenos; formação de poupança; produção e licenciamento de projetos e orientação técnica e intermediação. Foram organizadas 7 mil famílias em 68 cooperativas (DILIGENTI; FERNANDES; CAMPOS, 2017).

Outro programa da área habitacional citado pelos autores, que ocorreu na cidade de Porto Alegre, foi o Projeto Integrado Entrada da Cidade (PIEC), cujo objetivo era desenvolver ações voltadas à habitação e ao desenvolvimento urbano, socioeconômico e ambiental na Região Humaitá-Navegantes (DILIGENTI; FERNANDES; CAMPOS, 2017). Através do projeto PIEC foram construídas casas e lotes urbanizados.

O Programa de Reassentamento, produção de empreendimentos dotados de infraestrutura básica e solução habitacional, foi criado para famílias cujas casas estão em áreas impróprias para moradia. O Programa de Regularização Fundiária também foi uma ação conjunta entre sociedade civil e poder público local com o intuito de conferir título do terreno; dar acesso ao saneamento, pavimentação, iluminação pública, rede elétrica, enfim, todos os serviços públicos da cidade, além da construção de pequenos conjuntos habitacionais nas áreas já ocupadas pela população (DILIGENTI; FERNANDES; CAMPOS, 2017). Entre outras ações de participação popular no que se refere às demandas habitacionais que foram criadas no município de Porto Alegre, cita-se o Conselho Municipal de Acesso à Terra e Habitação (COMATHAB).

A partir dos anos 2000, houve um redirecionamento nas políticas de habitação no município de Porto Alegre. No ano de 2002 foram firmadas novas parcerias entre a prefeitura e novos órgãos como HBB-BID (Programa Habitar Brasil/BID - Programa de Habitação no Brasil com fundos do Banco Interamericano de Desenvolvimento e do Governo Federal, através do Ministério das Cidades) e o FONPLATA (Fondo Financiero para el Desarrollo de la Cuenca del Plata). E no ano de 2007,

[...] por exigência do Governo Federal e para que o município de Porto Alegre continuasse recebendo repasses para Habitação de Interesse Social (PMHIS, 2007), - DEMHAB como autarquia responsável pelo tema da Habitação Social foi encarregado da criação do PMHIS- Plano Municipal de Habitação de Interesse Social (DILIGENTI; FERNANDES; CAMPOS, 2017, p. 11). 
Tal iniciativa definia as diretrizes, objetivos, metas e estratégias de ação para superar o déficit habitacional de Porto Alegre, no que toca a população de baixa renda. Com o Minha Casa, Minha Vida, em 2009, os programas que existiam no município foram centralizados no programa federal. Para os autores, a substituição quase que absoluta dos programas municipais pelo Minha casa, minha vida, esvaziou as políticas locais. Além disso, percebeu-se que a política habitacional, o PMCMV, foi criada numa dinâmica de financeirização do território, fruto da decorrência do sistema mercadológico; outro aspecto foi a ausência de participação popular nas decisões e implementações da política pública de habitação. 0 problema da habitação de interesse social em Porto Alegre aumentou, e, junto a isso, também houve aumento populacional (DILIGENTI; FERNANDES; CAMPOS, 2017).

Assim, foram colocados dois modos de gerir os problemas relacionados à habitação. De forma democrática, a exemplo do COMATHAB (Conselho Municipal de Acesso à Terra e Habitação), que pelo tensionamento de movimentos sociais criou-se uma lei, em 1995, com potencial de modificar a forma como a habitação é produzida na cidade, ou seja, através dos conselhos e iniciativas de lei esperava-se romper com o processo de desigualdade. Por outro lado, tem-se a maneira centralizadora, representada pelo Minha Casa, Minha Vida, onde prevalece o modelo neoliberal em que o mercado dita as regras e a forma de onde e como as pessoas vão morar na cidade. Ao centralizar os recursos federais, tal programa acabou inibindo diversas iniciativas locais. Com a ascensão do Minha Casa, Minha Vida, o FMHIS, Fundo municipal de habitação de interesse social, perdeu sua força e passou a financiar apenas valores ínfimos de aluguel social e de bônus de moradia (DILIGENTI; FERNANDES; CAMPOS, 2017).

Sobre o caso de São Paulo, Maricato (1995 apud AMARAL, 2002) apresenta alguns dados sobre a cidade no final da década de 1980, no que diz respeito aos aspectos de moradias precárias. O que aparecia eram as moradias ilegais, favelas, casas em situações de risco ambiental. Nesse sentido, de acordo com Amaral (2002), a cidade de São Paulo,

[...] apresentava 40\% de sua população morando ilegalmente. Dentre 1.560 núcleos de favelas em 1987, 49,3\% tinham parte de sua área localizada à beira de córregos; $32,2 \%$ estavam sujeitos a enchentes; $29,3 \%$ situavam-se em terrenos com fortes declives; $24,2 \%$ erguiam-se sobre terrenos apresentando erosão acentuada; e 0,9\% encontravam-se em áreas de depósito de lixo ou de aterros sanitários (MARICATO, 1995 apud AMARAL, 2002, p. 17). 
Já a Secretaria da Habitação/Instituto de Pesquisas Tecnológicas de São Paulo (Sehab/IPT), em seu levantamento na época, obteve como resultado o fato de cerca de 12 mil famílias habitarem em áreas sujeitas aos desmoronamentos. A falta de cadastro dos loteamentos irregulares também demonstrava o agravamento do problema da precariedade e da vulnerabilidade da questão da moradia (AMARAL, 2002).

Em relação à questão da moradia, Maricato (2011) aponta que no final dos anos 1980, em quase todas as grandes cidades brasileiras havia um aumento da cidade informal, exigindo o aumento da máquina pública. Rolnik (2006, p. 204) afirma que o "planejamento e a gestão do solo urbano, na maior parte das cidades brasileiras, sempre esteve mais voltada para a cidade formal, raramente dialogando com os mercados de baixa renda".

As noções de cidade legal e cidade ilegal, ou de cidade formal e de cidade informal, são utilizadas por Maricato (2002) e Rolnik (2006) para explicar que a lógica do crescimento urbano produz uma divisão da cidade entre legal e ilegal ou entre formal e informal. Deste modo, por cidade legal define-se aquela parte da cidade que é assistida pelo poder público em relação aos aspectos de infraestrutura, sendo os territórios valorizados pelo mercado imobiliário. Por outro lado, a cidade ilegal é aquela em que a urbanização não chega, pelo contrário, são áreas em que há difícil acesso, áreas de ocupações ilegais. Espaços em que há dificuldade de mobilidade urbana, onde o transporte público não chega da mesma forma que na cidade formal. São áreas que faltam o saneamento básico e calçamento. Portanto, áreas de vulnerabilidade social e de precariedade da vida humana.

Sampaio e Pereira (2003) apontam que o surgimento das favelas acelerou-se no século XX, associado ao agravamento da situação habitacional, pois até o ano de 1973: [...] a porcentagem da população favelada sobre o total do Município correspondia a 1\%, esta parcela elevou-se a quase $8 \%$ em 1987, ou seja, em mais de $1.000 \%$, enquanto a população de São Paulo cresceu 60\% (SAMPAIO; PEREIRA, 2003, p. 169).

Em 1989, quando iniciou o mandato de um novo governo municipal em São Paulo, alguns princípios foram estabelecidos para tratar da política de habitação e enfrentar os impasses que se apresentavam. Alguns deles:

[...] direito à terra; direito à arquitetura; direito à cidadania; participação da população na formulação dos programas e execução dos projetos; diversificação das intervenções, reconhecimento da cidade real; redução de custos, sem perda da qualidade; estímulo à autogestão e respeito ao meio ambiente (AMARAL, 2002, p. 19). 
Cabe destaque, entre os princípios apresentados, o item participação da população na formulação dos programas e execução dos projetos. Como se tratava do primeiro governo após um regime ditatorial vigente no país, havia grandes desafios, sobretudo em relação à democratização das esferas sociais.

O Fundo de Atendimento à População Moradora de Habitação Subnormal (FUNAPS) foi criado pela Lei no 8.906, sancionada em 1979, portanto, durante o regime ditatorial. Tratava-se de um fundo destinado para melhoria das condições de vida da população de baixa renda. No início do governo municipal, afirma Amaral (2002, p. 19), "a Superintendência de Habitação serviu como instrumento da prefeitura na concepção e execução da política de habitação social, sendo responsável pela administração do FUNAPS".

Até o final dos anos 1980, tal fundo contava com uma estrutura administrativa restrita, supervisionado por um Conselho do Fundo, e "seu objetivo consistia em financiar atendimentos individualizados." (AMARAL, 2002, p. 19). Tal modelo foi modificado, a partir de 1989, quando houve uma ampliação da estrutura administrativa da Superintendência de Habitação, "fortalecendo escritórios regionais em toda a cidade, buscando parcerias para a definição e execução da política e consolidando canais de participação popular." (AMARAL, 2002, p. 19).

No caso do município de São Paulo, Maricato (2011) relata que o crescimento da cidade informal exigiu uma presença do Estado de modo que a questão da habitação social fosse atendida. Maricato (2011, p. 20) aponta que a mudança na estrutura da Sehab (Secretaria de Habitação) "enfrentou muita resistência, mas teve nos movimentos de moradia uma forte alavanca impulsionadora". A mesma autora relata que, durante os dois primeiros anos de governo, "semanal ou mensalmente havia uma ocupação da Sehab, por parte de algum dos movimentos paulistanos, exigindo maior velocidade nas ações." (MARICATO, 2011, p. 21).

Inverter as prioridades era a palavra de ordem dos movimentos populares, que, de acordo com Maricato (2011), significava transformar o orçamento e os procedimentos, ou seja, tornar a máquina do Estado realmente instituição pública.

Entre as prioridades dadas pelo governo constavam o de direcionar recursos municipais para habitação de interesse social, "uma vez que os recursos federais e estaduais existentes estavam politicamente inacessíveis para a Prefeitura do Município de São Paulo." (AMARAL, 2002, p. 20). Nessa perspectiva, em 1992, pelo Decreto de Habitação de Interesse Social - HIS, as discussões sobre a produção de habitações de interesse social foram 
normatizadas. Entre as medidas tomadas para enfrentar a questão da moradia e produzir políticas de habitação de interesse social, houve a criação do Funaps Comunitário. Através do Funaps comunitário, buscou-se estimular a autogestão nos empreendimentos financiados pelo município. Desse modo, eram propostas ações em parceria entre associações de mutirantes, organizações não governamentais que prestavam assessoria técnica, ONGs e administração pública (AMARAL, 2002).

Os movimentos sociais que reivindicavam o direito à moradia buscavam espaços democráticos para discutir as políticas de habitação. Tais agentes sociais visavam atuar em todo processo de gestão da produção do conjunto habitacional, "desde a indicação do terreno, a definição do projeto, a realização da obra, reconhecendo e valorizando a capacidade gerencial das famílias." (AMARAL, 2002, p. 22). Através do programa e de sua atuação em conexão com diversos agentes da sociedade civil, foram construídas unidades habitacionais, "com redução do custo em torno de 50\% do valor praticado pelas empreiteiras" (AMARAL 2002, p. 22).

O ponto marcante e o resultado dessa maneira de se fazer política foi o fortalecimento de novas lideranças da sociedade civil e as experiências de organização e gestão popular. Amaral (2002) ressalta que a relação entre poder público e movimentos populares foi implementada no cotidiano, e tal relação foi determinante para que acontecesse a intervenção em diversos âmbitos da política habitacional, tais como: na indicação de terrenos, discussão de projetos, guarda das áreas desapropriadas, gestão do empreendimento, organização da população para possibilitar a urbanização de favelas, ente outros:

\footnotetext{
Como forma de institucionalizar a participação popular, foi amplamente discutida a criação de um Conselho Municipal de Habitação Popular, debate que gerou uma proposta de articulação entre conselhos regionais e conselhos temáticos, definidos de acordo com as características gerais da cidade (favela, cortiço, mutirão, população sem moradia, mutuário do fundo e questões de uso e ocupação do solo) (AMARAL, 2002, p. 22).
}

Assim, percebe-se como a política de habitação é produzida de maneira em que há participação direta da população, sobretudo, das pessoas que vivem o problema no dia a dia. O movimento percebido por este processo realizado em São Paulo foi do envolvimento no cotidiano das ruas até a criação do Conselho Municipal de Habitação Popular. Em outras palavras, criou-se um espaço na esfera do poder público em que as pessoas pudessem atuar 
a fim de construir a política pública de habitação. No ano de 1994, "foi aprovada a Lei no 11.632, que dispunha sobre a política municipal de habitação voltada à população de baixa renda. Essa lei instituía o Fundo Municipal de Habitação e criava o Conselho do Fundo Municipal de Habitação." (AMARAL, 2002, p. 29).

No entanto, houve conflitos de diversas ordens, desde jurídicos aos executivos e estruturais da própria sociedade paulista. Outro aspecto problemático foi o de como dar continuidade e desenvolver políticas de participação popular, visto que, num período de quatro anos, considera-se um curto tempo para consolidar uma política pública de habitação, tendo em vista que suas ações mexem com uma estrutura social, muitas vezes já fortalecida. Além disso, havia um conflito de interesses no jogo político, por exemplo, entre a prefeitura e a câmara de vereadores, no caso paulista, tal como aponta a autora:

Durante todo o governo, as relações com a Câmara Municipal foram conflituosas e impediram alterações necessárias na legislação. Instrumentos importantes para a consolidação de uma nova política habitacional, como o Conselho de Habitação, foram inviabilizados (AMARAL, 2002, p. 26).

Embora tenha havido um vínculo entre o poder público com amplos setores de movimentos sociais, muitas barreiras foram encontradas para que essa relação se solidificasse. A cidade é um espaço social, onde há diversos agentes e grupos com diferentes interesses, e, muitas vezes, esses interesses não convergem. Se para alguns a cidade é vista como um espaço de relação em que há uma história familiar e cultural que confere sentido para a vida, localizada num determinado espaço da cidade; para outros, a cidade é uma mercadoria, um espaço em que deve prevalecer os diferentes modos de mercantilização do solo, ou seja, o significado da cidade está naquilo que ela pode oferecer como lucro para o indivíduo. Esses dois modelos conflitam no espaço político.

\section{Considerações Finais}

As manifestações populares que reivindicam melhores condições de vida na cidade, que reivindicam o direito à moradia, estão situadas numa visão de cidade em que o modo de produção capitalista prevalece hegemônico. Nota-se que as experiências de Porto Alegre e São Paulo foram importantes para que na cena pública atuasse um sujeito coletivo, representado pelos movimentos populares que buscam construir a concretização do direito que, por vezes, permanece em sua abstração jurídica. Nesse sentido, parece convergir dois 
modelos de políticas de habitação em solos brasileiros: um mais centralizado, que desde o BNH até o MCMV tem dominado o espaço social; e outro, mais local, abordado nesse texto pelos casos de Porto Alegre e São Paulo. Neles, a via do Orçamento Participativo e a via que conferiu espaço para que os movimentos populares lidassem de maneira direta com a problemática da moradia e da produção da política aparecem como paradigmas contrastantes ao modelo da democracia representativa hegemônica na história do Brasil.

A implementação do Orçamento Participativo em Porto Alegre, no ano de 1989, com questões relacionadas à habitação, além da criação de novos programas e projetos locais para a cidade, realizados através do Departamento Municipal de Habitação Social (DEMHAB) com o financiamento do Fundo Municipal de Habitação significou o desenvolvimento de uma política habitacional em que participação popular lidava diretamente com as questões de habitação. Durante os anos 1990 outras políticas foram desenvolvidas em Porto Alegre. Entre elas foram destacadas o Programa de Regularização Fundiária, o Programa de Cooperativismo Habitacional Autogestionário, o Projeto Integrado Entrada da Cidade (PIEC), entre outras, apontando o caráter da política habitacional centrada na participação popular.

No caso de São Paulo, também nos anos 1990, as políticas habitacionais tiveram em seu marco local um destaque no processo democrático com o qual tais políticas foram produzidas. Nesse sentido foi apontado o Decreto de Habitação de Interesse Social, a criação do Funaps Comunitário, que buscou estimular a autogestão nos empreendimentos financiados pelo município, mas, em parceria com associações de mutirantes, ONGs que prestavam assessoria técnica e administração pública. O caso de São Paulo também foi marcado pela participação popular e pelo fortalecimento de lideranças da sociedade civil que se envolveram no processo de produção de políticas habitacionais e de organização popular na cidade.

No entanto, diante da última grande política de habitação, o Minha Casa, Minha Vida, os modelos implementados em São Paulo e Porto Alegre tais experiências tiveram alguns retrocessos. Nesse sentido, o PMCMV repetiu o aspecto centralizador que esteve presente no BNH. Com a centralização de ações houve um distanciamento da participação e da decisão dos rumos da política habitacional da sociedade civil. O modelo das políticas habitacionais centralizadas teve um relevante espaço ocupado pelas empresas, sobretudo, ligadas à construção civil.

Em contrapartida, as experiências de São Paulo e Porto Alegre criaram condições para que as organizações populares e os movimentos sociais participassem do processo, 
conferindo o aspecto democrático da política de habitação. Vale salientar que esse período foi marcado também pela Emenda popular pela Reforma Urbana (1988) e pelo primeiro projeto de lei de iniciativa popular, o Fundo Nacional de Moradia Popular, em 1992. Tais aspectos apontam que a relação entre poder público, participação popular e a presença técnica de urbanistas e arquitetos, por exemplo, engajados com a cidadania, sugerem que é possível construir políticas públicas de habitação de caráter democrático.

\section{Referências}

AMARAL, Ângela de Arruda Camargo. Habitação na cidade de São Paulo. 2. ed. São Paulo: Pólis, 2002. (Observatório dos direitos do cidadão: acompanhamento e análise das políticas públicas da cidade de São Paulo, 4).

BÖHM, Thais. Minha Casa Minha Vida não reduziu deficit habitacional, afirma estudo. Jornal do Senado, Brasília, ano 14, n. 622, 20 fev. 2018. Disponível em:

https://www2.senado.leg.br/bdsf/bitstream/handle/id/538499/Cidadania_622.pdf?sequenc e=1. Acesso em: 10 jul. 2020.

BOLAFFI, Gabriel. Habitação e urbanismo: o problema e o falso problema. In: MARICATO, Ermínia (org.). A produção capitalista da casa (e da cidade) no Brasil industrial. 2. ed. São Paulo: Alfa-Omega, 1982. p. 37-70.

BRASIL. [Constituição (1988)]. Constituição da República Federativa do Brasil de 1988. Brasília: Presidência da República, 1988. Disponível em:

http://www.planalto.gov.br/ccivil_03/constituicao/constituicao.htm. Acesso em: 1 jun. 2019.

BRASIL. Lei no 11.124, de 16 de junho de 2005. Dispõe sobre o Sistema Nacional de Habitação de Interesse Social - SNHIS, cria o Fundo Nacional de Habitação de Interesse Social - FNHIS e institui o Conselho Gestor do FNHIS. Brasília: Presidência da República, 2005. Disponível em: http://www.planalto.gov.br/ccivil_03/_Ato2004-2006/2005/Lei/L11124.htm. Acesso em: 22 mar. 2019.

BRASIL. Ministério das Cidades. Secretaria Nacional de Habitação. Política Nacional de Habitação. Brasília: Ministério das Cidades, 2004. Disponível em:

http://www.cidades.gov.br/images/stories/ArquivosSNH/ArquivosPDF/4PoliticaNacionalHab itacao.pdf. Acesso em: 22 jul. 2019.

DILIGENTI, Marcos Pereira; FERNANDES, Idilia; CAMPOS, Tiago de. Habitação de interesse social em Porto Alegre: um estudo retrospectivo das políticas municipais. Serviço Social em Revista, Londrina, v. 20, n. 1, 2017. Disponível em:

http://www.uel.br/revistas/uel/index.php/ssrevista/article/view/32160. Acesso em: 15 set. 2019.

FUNDAÇÃO JOÃO PINHEIRO. Fundação João Pinheiro divulga resultados do Déficit Habitacional no Brasil. Belo Horizonte: FJP, 2018. Disponível em: 
http://www.fjp.mg.gov.br/index.php/noticias-em-destaque/4154-fundacao-joao-pinheirodivulga-resultados-do-deficit-habitacional-no-brasil. Acesso em: 13 jul. 2019

GOMES, Maria de Fatima Cabral Marques. Habitação e questão social: análise do caso brasileiro. Revista Electrónica de Geografía y Ciencias Sociales, Barcelona, v. 9, n. 194, 2005. Disponível em: http://www.ub.edu/geocrit/sn/sn-194-26.htm. Acesso em: 22 jul. 2019.

MARICATO, Ermínia. As ideias fora do lugar e o lugar fora das ideias: planejamento urbano no Brasil. In: ARANTES, Otília; VAINER, Carlos; MARICATO, Ermínia. A cidade do pensamento único: desmanchando consensos. Petrópolis: Vozes, 2002. p. 121-192.

MARICATO, Ermínia. Metrópole, legislação e desigualdade. Estudos Avançados, São Paulo, v. 17, n. 48, maio/ago. 2003.

MARICATO, Ermínia. Moradia urbana tem que levar em consideração a política urbana, principalmente de terra urbana. [Entrevista cedida a Wagner Fernandes de Azevedo]. In: INSTITUTO HUMANITAS UNISINOS. São Leopoldo, 31 mar. 2019. Disponível em: http://www.ihu.unisinos.br/159-noticias/entrevistas/587974-moradia-urbana-tem-quelevar-em-consideracao-a-politica-urbana-principalmente-de-terra-urbana-entrevistaespecial-com-erminia-maricato. Acesso em: 27 set. 2019.

MARICATO, Ermínia. O impasse da política urbana no Brasil: Petrópolis: Vozes, 2011.

RAMOS, Jefferson da Silva; NOIA, Angye Cássia. A construção de políticas públicas em habitação e o enfrentamento do déficit habitacional no Brasil: uma análise do programa Minha Casa Minha Vida. Desenvolvimento em Questão, ljuí, v. 14, n. 33, p. 65-105, 2016. Disponível em:

https://www.revistas.unijui.edu.br/index.php/desenvolvimentoemquestao/article/view/319 4. Acesso em: 2 jul. 2019.

RIBEIRO, Gilvane Mazza. O déficit habitacional no Brasil diante do impacto da crise mundial. In: JORNADA INTERNACIONAL DE POLÍTICAS PÚBLICAS, 6., 2013, São Luiz. Anais [...]. São Luiz: UFMA, 2013. Disponível em:

http://www.joinpp.ufma.br/jornadas/joinpp2013/JornadaEixo2013/anais-eixo13questaourbanaegestaodascidades/odeficithabitacionalnobrasildiantedoimpactodacrisemund ial.pdf. Acesso em: 22 jul. 2019.

ROLNIK, Raquel. A construção de uma política fundiária e planejamento urbano para o país: avanços e desafios. Políticas Sociais: Acompanhamento e Análise, Brasília, n. 2, p. 199-210, fev. 2006. Disponível em:

http://repositorio.ipea.gov.br/bitstream/11058/4507/1/bps_n.12_constru\%c3\%a7\%c3\%a3o. pdf. Acesso em: 2 nov. 2019.

ROLNIK, Raquel. Guerra dos lugares. São Paulo: Boitempo, 2015.

RUBIN, Graziela Rossatto; BOLFE, Sandra Ana. O desenvolvimento da habitação social no Brasil. Ciência e Natura, Santa Maria, v. 36, n. 2, p. 201-213, maio/ago. 2014. Disponível em: http://oaji.net/articles/2017/1602-1487076445.pdf. Acesso em: 22 jul. 2019. 
SAMPAIO, Maria Ruth Amaral de; PEREIRA, Paulo Cesar Xavier. Habitação em São Paulo. Estudos Avançados, São Paulo, v. 17, n. 48, p. 167-183, 2003. Disponível em:

http://www.revistas.usp.br/eav/article/view/9929/11501. Acesso em: 2 nov. 2019.

SANTOS, Mauricleia Soares dos. Atual política nacional de habitação: garantia de direito. In: JORNADA INTERNACIONAL DE POLÍTICAS PÚBLICAS, 2., 2005, São Luiz. Anais [...]. São Luiz: UFMA, 2005. Disponível em:

http://www.joinpp.ufma.br/jornadas/joinppll/pagina_PGPP/Trabalhos2/mauricleia_Soaredo s_Santos322.pdf. Acesso em: 29 jul. 2019.

SANTOS, Milton. A urbanização brasileira. São Paulo: Hucitec, 1993. 